\title{
Noga Efrati
}

\section{COMPETING NARRATIVES: HISTORIES OF THE WOMEN'S MOVEMENT IN IRAQ, 1910-58}

The history of the women's movement in Iraq before 1958 has received little attention in contemporary scholarly literature published in English. Moreover, when surveying the brief accounts in secondary sources, one is struck by their inconsistency. Upon closer examination, two historiographical approaches emerge. One primarily follows the development of women's activities sanctioned by the regime, focusing on organizations and activists associated with the Iraqi Women's Union, established in 1945. The second approach traces developments and organizations linked with the underground League for the Defense of Women's Rights, founded in 1952. This essay argues that members of the rival union and league constructed two competing narratives in presenting the history of the women's movement in pre-1958 Iraq. The article unpacks these two different narratives as they were originally articulated by activists in order to piece together a more elaborate portrayal of the evolution of the early Iraqi women's movement. The essay also explores how scholars have reproduced these narratives, arguing that both activists and researchers were active participants in a "war of narratives" that left women's history the unfortunate casualty. 